Revue

Revue de l'histoire des religions

de Ihistoire des religions

Le légendier de Moissac et la culture hagiographique méridionale autour de l'an mil, Fernand PeLOUX (éd.)

Turnhout, Brepols (« Hagiologie », 15), 2018

Sébastien Fray

\title{
OpenEdition
}

Journals

Édition électronique

URL : https://journals.openedition.org/rhr/11349

DOI : $10.4000 /$ rhr. 11349

ISSN : 2105-2573

Éditeur

Armand Colin

Édition imprimée

Date de publication : 1 septembre 2021

Pagination : $562-564$

ISBN : 978-2-200-93377-7

ISSN : 0035-1423

Référence électronique

Sébastien Fray, «Le légendier de Moissac et la culture hagiographique méridionale autour de l'an mil, Fernand Peloux (éd.) ", Revue de l'histoire des religions [En ligne], 3 | 2021, mis en ligne le 01 septembre 2021, consulté le 04 octobre 2021. URL : http://journals.openedition.org/rhr/11349 ; DOI : https:// doi.org/10.4000/rhr.11349

Ce document a été généré automatiquement le 4 octobre 2021.

Tous droits réservés 


\section{Le légendier de Moissac et la culture hagiographique méridionale autour de l'an mil, Fernand Peloux (éd.)}

Turnhout, Brepols (« Hagiologie », 15), 2018

\section{Sébastien Fray}

\section{RÉFÉRENCE}

Le légendier de Moissac et la culture hagiographique méridionale autour de l'an mil, Fernand Peloux (éd.), Turnhout, Brepols (« Hagiologie », 15), 2018, 580 p., 52 ill., 24 cm, $95 €$, ISBN 978-2-503-58174-3.

1 L'ouvrage dirigé par Fernand Peloux prend place dans un manuscript turn des études hagiologiques, impulsé par Guy Philippart (auquel le livre est dédié), François Dolbeau et Martin Heinzelmann. La notion de culture hagiographique, qui mériterait d'être précisée plus fermement, rend compte de ce déplacement: ce n'est plus l'existence historique des saints, l'histoire de leur culte, l'intérêt pour les hagiographes, qui servent de fil conducteur, mais bien le manuscrit hagiographique lui-même (ici un légendier de Moissac daté du XI ${ }^{\mathrm{e}}$ siècle), exemple de document-monument (au sens où l'entendent Jacques Le Goff et Pierre Toubert) qui donne lieu à une histoire totale.

De très nombreux aspects de l'histoire du légendier de Moissac sont abordés, toujours de façon excellente, les études étant servies par une iconographie couleur très riche qui sert de point d'appui aux démonstrations : mise en contexte dans le cadre de l'abbaye de Moissac et de la société environnante (Didier Panfili), structure codicologique (Charlotte Denoël), décors (Chantal Fraïsse), contenu (F. Peloux) et sources mobilisées (F. Peloux, Monique Goullet), additions musicales (Gisèle Clément), dimension linguistique (Michel Banniard).

3 Refusant résolument tout enfermement monographique, la deuxième partie de l'ouvrage permet de multiplier les comparaisons entre le légendier de Moissac et 
d'autres collections hagiographiques : un légendier aquitain perdu (François Dolbeau), deux collections hagiographiques du début du xIV siècle (Hiromi Haruna-Czaplicki, Agnès Dubreil-Arcin). Appuyés sur des annexes descriptives fort utiles, ces deux articles soulignent notamment comment le légendier de Moissac a servi à Bernard Gui pour élaborer son Speculum sanctorale.

Des études de cas érudites et minutieuses d'un certain nombre de textes rares contenus dans le légendier permettent de renforcer l'ouverture à d'autres horizons. On rencontre bien entendu un certain nombre de saints méridionaux dont les dossiers sont à l'honneur: saint Saturnin (Anne-Véronique Gilles-Raynal), les saints gascons (Christophe Baillet). Mais il faut également compter avec la présence de textes qui renvoient à des régions plus lointaines, dont l'étude des circulations est passionnante : la passion de saint Vamnes, un martyr perse (Christelle Julien), la diffusion des passions de martyrs africains en Gaule méridionale (Sabine Fialon), les textes consacrés aux saints bourguignons (Charles Mériaux).

5 L'ouvrage n'oublie pas de réinscrire le légendier de Moissac dans une perspective pragmatique, qui recoupe l'histoire du monastère lui-même durant le Moyen Âge. F. Peloux a examiné les usages possibles du manuscrit aux $\mathrm{XI}^{\mathrm{e}}$ et $\mathrm{xII}^{\mathrm{e}}$ siècles, par comparaison avec d'autres manuscrits hagiographiques de Moissac, ainsi que la place que le légendier a tenue dans l'évolution de la mémoire moissagaise, y compris au bas Moyen Âge. La liste des saints mentionnés dans le manuscrit a également été comparée avec les riches listes de reliques de Moissac jusqu'au XvI ${ }^{\mathrm{e}}$ siècle (F. Peloux et Taiichiro Sugizaki, secondés par Emmanuel Moureau). Tout au plus peut-on regretter que l'analyse ne pousse pas jusqu'à la première moitié du XvII siècle (mais peut-être que les sources ne le permettaient pas) : il aurait été intéressant de savoir ce qui avait conduit Moissac à abandonner le manuscrit à Claude Joly, chanoine et chantre de Notre-Dame de Paris, en 1656.

6 Cet ouvrage dense et bien organisé, collectif mais cohérent (et on sent à la lecture tout le mal que s'est donné $\mathrm{F}$. Peloux pour assurer cette cohérence), intelligemment illustré, aux scories éditoriales peu nombreuses, présente un grand intérêt épistémologique. Le pari de faire une histoire totale du légendier moissagais est tout à fait réussi. Il met en œuvre une autre pratique de l'histoire, dans laquelle c'est la trajectoire même du document au fil des siècles qui est placée au centre de l'intrigue : non par goût d'une érudition repliée sur elle-même, mais parce que l'approche à la fois diachronique et synchronique du document (de sa conception à ses multiples usages et réceptions) nous en apprend beaucoup sur les générations successives d'hommes qui l'ont eu entre les mains, l'ont manipulé ou négligé, conservé et transmis. 


\section{AUTEURS}

\section{SÉBASTIEN FRAY}

Université Jean Monnet, Saint-Étienne, Laboratoire d'études sur les monothéismes Institut d'Histoire des Représentations et des Idées dans les Modernités. 